\title{
Öğretmen Adaylarının Öğrenme Yaklaşımları ve Ölçme ve Değerlendirme Tercihleri Arasındaki İlişkinin İncelenmesi
}

\section{Investigating the Relationship between Learning Approaches and Assessment Preferences among Pre-service Teachers}

\author{
Pinar KARAMAN*
}

Received: 22 May 2018

Research Article

Accepted: 03 December 2018

ABSTRACT: The purpose of this study is to examine the relationship between the pre-service teachers' approaches to learning and assessment preferences. Relational model was used in this study. The participants of the study consisted of 264 pre-service teachers who enrolled in one of the teacher education programs in Turkey during the 2016-2017 academic years. The data of the study was obtained by the implementation of two different scales. In order to assess pre-service teachers' approaches to learning, "Revised Two-factor Study Process Questionnaire" adapted to Turkish culture by Önder and Beşoluk (2010) was used. When it comes to determining pre-service teachers' assessment preferences, “Assessment Preferences Inventory” adapted to Turkish culture by Gülbahar and Büyüköztürk (2008) was utilized. Canonical correlation analysis was performed to determine the relationship between learning approaches data set composed of deep approach to learning and surface approach to learning variables and assessment preferences data set composed of traditional, alternative, complex-constructivist, and simple-multiple choice variables. The results showed that significant relationships existed between approaches to learning and assessment preferences of pre-service teachers.

Keywords: approaches to learning, assessment preferences, canonical correlation.

ÖZ: Bu çalışmanın amacı öğretmen adayların öğrenme yaklaşımları ile ölçme ve değerlendirme tercihleri arasındaki ilişkilerinin belirlenmesidir. Bu amaca uygun olarak araştırmada ilişkisel tarama modeli kullanılmıştır. Araştırmanın çalışma grubunu, 2016-2017 öğretim yılında Türkiye'nin bir eğitim fakültesinde öğrenim gören 264 öğretmen aday1 oluşturmaktadır. Öğretmen adaylarının öğrenme yaklaşımlarını ölçmek için Önder ve Beşoluk (2010) tarafından Türkçe'ye uyarlanan “Düzenlenmiş İki Faktörlü Çalışma Süreci Ölçeği” kullanılmıştır. Adayların ölçme ve değerlendirme tercihlerini ölçmek için ise Gülbahar ve Büyüköztürk (2008) tarafindan Türkçe'ye uyarlanan "Ölçme ve Değerlendirme Tercihleri Ölçeği” kullanılmıştır. Öğrenme yaklaşımları veri setinde yer alan derin öğrenme ve yüzeysel öğrenme değişkenleri ile ölçme ve değerlendirme tercihleri veri setinde yer alan geleneksel değerlendirme yöntemleri, alternatif değerlendirme yöntemleri ve karmaşık-oluşturmacı, basit-seçmeli sınav türlerinden oluşan değişkenler arasındaki ilişki kanonik korelasyon analizi ile incelenmiştir. Kanonik korelasyon analizi sonucunda, öğretmen adaylarının benimsemiş oldukları öğrenme yaklaşımları ile ölçme ve değerlendirme tercihleri arasında anlamlı bir ilişki olduğu ortaya çıkmıştır.

Anahtar kelimeler: öğrenme yaklaşımları, ölçme ve değerlendirme tercihleri, kanonik korelasyon.

\footnotetext{
*Asst. Prof. Dr., Sinop University, Sinop, Turkey, pkaraman1626@gmail.com
}

\section{Citation Information}

Karaman, P. (2019). Öğretmen adaylarının öğrenme yaklaşımları ve ölçme ve değerlendirme tercihleri arasındaki ilișkinin incelenmesi. Kuramsal Eğitimbilim Dergisi [Journal of Theoretical Educational Science], 12(1), 135-150. 


\section{Giriş}

21. yüzyılda yükseköğretimde öğretim uygulamalarının öğrenci gelişimini sağlayacak şekilde geliştirilmesi gittikçe önem kazanmaktadır. Üniversite öğrencilerinin profesyonel hayatlarına donanımlı bir şekilde hazırlanabilmesi için eğitim-öğretim süreçlerinde bilgiye etkili bir şekilde ulaşabilme, eleştirel düşünebilme, analiz, sentez yapabilme, çıkarımda bulunma gibi yaşam boyu öğrenme becerilerini geliştirmeleri amaçlanmaktadır. Üniversite öğrencilerinin bu üst düzey becerilere ulaşabilmesi için derin öğrenme yaklaşımını benimsemiş olmaları oldukça önemlidir (Asikainen, 2014; Segers, Dochy, \& Cascallar, 2003).

Öğrenme yaklaşımı kavramı ilk olarak Marton ve Saljo (1976) tarafından yapılan nitel bir çalışma ile ortaya atılmıştır. Araştırmada üniversite öğrencilerine okuma parçası verilerek öğrenme süreçlerindeki farklılıkları ortaya çıkarmak amaçlanmıştır. Araştırmada bir grup öğrencinin okudukları metni anlamadan aktarma, ezberleme eğiliminde oldukları diğer grubun ise okudukları metni bir bütün olarak ele alarak içeriği detaylı bir şekilde anlama eğiliminde oldukları ortaya çıkmıştır. Marton ve Saljo (1976), bu grupların öğrenmeyi farklı niyetlerle ve biçimlerle ele almalarından dolayı öğrenme yaklaşımlarını, yüzeyesel öğrenme ve derin öğrenme yaklaşımı olarak adlandırmıştır. Psikolojik bir özellik olarak tanımlanan öğrenme yaklaşımları, öğrencilerin kişisel özelliklerinin yanında öğrencilerin bulundukları öğrenme ortamına, öğrenme-öğretme sürecinde aldıkları görevlere ve kullanılan ölçme ve değerlendirme yöntemlerine bağlı olarak değişebilmektedir (Biggs \& Tang, 2007; Marton \& Saljo, 1976; Ramsden, 1984; Scouller \& Prosser, 1994). Yapılandırmacı öğrenme kuramının önemli bir hedefi olan derin ve anlamlı öğrenme yaklaşımı (De Corte, 1996), yansıtıcı ve detaylı bir öğrenme yaklaşımı iken yüzeysel öğrenme yaklaşımı tekrara dayalı bir öğrenme yaklaşımıdır. Derin öğrenen öğrenci, içeriğe ayrıntılı olarak çalışarak bilgiyi yapılandırır ve tam anlamıyla öğrenmeyi hedeflemektedir. Önceki bilgileri ile yeni bilgilerini ilişkilendirir, öğrenilen konuları güncel hayatla ilişkilendirir, tartışır ve yansitma yapmaktadir (Birenbaum \& Rosenau, 2006; Byrne, Flood, \& Willis, 2002). Derin öğrenme yaşam boyu öğrenmenin önemli bir parçasıdır (Birenbaum, 2007). Araştırmalar derin öğrenme ile öğrenci başarısı arasında pozitif bir korelasyon olduğunu göstermektedir (Heikkila \& Lonka, 2006; Watkins, 2001). Ancak öğrencilerin derin öğrenme yaklaşımlarını etkili bir şekilde kullanabilmesi karmaşık bir süreçtir (Baeten, Dochy, \& Struyven, 2008; Ramsden, Beswick, \& Bowden, 1986). Yüzeysel öğrenen öğrenci ise içeriği ezberleyerek ya da tekrar ederek sadece ders için asgari şartları yerine getirmeyi hedeflemektedir (Marton \& Saljor,1976; Gijbels, van de Watering, Dochy, \& Van den Bossche, 2005). İçeriği derin bir şekilde anlamak için problem çözme, düşünme, sorgulama gibi becerilere yönelmediği görülmektedir. Derin ve yüzeysel öğrenme yaklaşımının yanında sonraki yıllarda Biggs (1987) tarafından üçüncü bir öğrenme yaklaşımı türü olarak başarı yaklaşımı ortaya konmuştur. Stratejik öğrenme yaklaşımı olarak da adlandırılan bu yaklaşımda, öğrenciler yüksek not alabilmek için bulundukları öğrenme ortamının özelliklerini dikkate alarak hem derin hem de yüzeysel öğrenme yaklaşımını kullanabilmektedir (Diseth \& Martinsen, 2003). 
Öğrencilerin derin ya da yüzeysel öğrenme yaklaşımları öğrenme ortamında birçok faktöre bağlı olarak değişebilmektedir. Eğitim-öğretim sürecinde almış oldukları görevler (Biggs, 2001; Ramsden, 1984; Segers, Martensa, \& Bossche, 2008; Ünal \& Ergin, 2006), kullanılan ölçme değerlendirme yöntemleri öğrencilerin öğrenme yaklaşımlarını etkileyebilmektedir (Gibbs, 1999; Ramsden, 1992; Scouller \& Prosser, 1994; Trigwell \& Prosser, 1991). Ayrıca öğrencilerin öğrenme ortamında bu faktörlere ilişsin düşünceleri, öğrencilerin sahip oldukları özellikler de öğrenme yaklaşımlarını etkileyebilmektedir (Gijbels, Donche, Richardson, \& Vermunt, 2014).

\section{Öğrenme Yaklaşımları ve Ölçme ve Değerlendirme Tercihleri Arasındaki İlişki}

Yapılandırmacı yaklaşımın etkisi ile öğrenmede yaşanan değişim ölçme ve değerlendirmede de önemli değişim getirmiştir. Günümüzdeki yeni ölçme ve değerlendirme yaklaşımı sadece öğretim sürecinde öğrencilerin geçip kaldığına ya da başarılı olup olmadığına karar verebilmek için kullanılmamakta aynı zamanda öğrenci gelişimini sağlayan ve öğrenmeye katkıda bulunan bir araç olarak da kullanılmaktadır. Buna göre ölçme ve değerlendirmede iki yaklaşım söz konusudur; öğrenme odaklı ya da süreç odaklı ölçme ve değerlendirme yaklaşımı ve ürün odaklı ölçme ve değerlendirme yaklaşımı. Öğrenme odaklı ölçme ve değerlendirme yeni bir ölçme ve değerlendirme kültürü olup öğrenme, öğretme ve ölçme değerlendirme öğelerinin birleşmesine katkıda bulunmaktadır (Segers, Dochy, \& Cascallar, 2003). Yapılandırmacı öğrenme kuramının etkisiyle öğretimin önemli bir parçası olarak görülen bu ölçme ve değerlendirme yaklaşımı (Biggs, 1996), derin öğrenme gelişimine katkıda bulunan önemli bir araçtır (Dochy \& McDowell, 1997; Gulikers, Bastiaens, Kirschner \& Kester, 2006). Ürün odaklı ölçme ve değerlendirme ise daha çok yüzeysel öğrenme yaklaşımına katkıda bulanabilmektedir (Al-Kadri, Almoamary, Roberts, \& Van der Vleuten, 2012; Sambell, McDowell \& Brown, 1997). Bu nedenle, öğrenme ortamında niteliği arttırabilmek için öğrencilerin öğrenme, öğretme ve ölçme ve değerlendirme yöntemlerine yönelik düşüncelerinin ve tercihlerinin incelenmesi oldukça önemlidir (Sander, Stevenson, King, \& Coates, 2000).

Yapılan çeşitli araştırmalar öğrencilerin öğrenme yaklaşımları ile ölçme ve değerlendirme tercihleri arasında ilişki olduğunu göstermektedir (Birenbaum 1997; Birenbaum \& Feldman, 1998; Birenbaum \& Rosenau, 2006; Doğan, Atmaca, \& Aslan, 2012; Gijbels \& Dochy, 2006; Gijbels, Segers, \& Struyf, 2008; Schouller, 1998; Segers, Nijhuis, \& Gijselaers, 2006; Segers, Martens, \& Bossche, 2008). Birenbaum ve Feldman'ın (1998) çalışmasında, derin öğrenme yaklaşımına sahip öğrencilerin diğer değerlendirme türlerine göre daha çok açık uçlu soruları tercih ettikleri, yüzeysel öğrenme yaklaşımına sahip öğrencilerin ise daha çok çoktan seçmeli türündeki soruları tercih ettikleri tespit edilmiştir. Gijbels ve Dochy (2006) ise çalışmalarında öğrencilere süreç odaklı ölçme ve değerlendirme uygulamaları yaptırmışlardır. Uygulama öncesinde ve sonrasında öğrenme yaklaşımları ve ölçme değerlendirme tercihleri arasındaki ilişki incelenmiştir. Öğrencilerin süreç odaklı ölçme ve değerlendirme deneyimleri sonrasında derin öğrenme yaklaşımları ile alternatif değerlendirme tercihleri arasında pozitif bir ilişki ortaya çıkmıştır. Bununla birlikte, öğrencilerin deneyimleri sonrası derin öğrenme yaklaşımları ile geleneksel değerlendirme tercihleri arasında ise negatif bir ilişki olduğu ortaya çıkmıştır. Bu alana yönelik gerek yurt içi gerek yurt dışında yapılan çalışmaların 
sınırlı olması nedeniyle daha fazla araştırma yapılarak öğrencilerin öğrenme yaklaşımları ve ölçme ve değerlendirme tercihleri arasındaki ilişkilerinin anlaşılması gerekmektedir. Bu araştırmada, öğretmen adaylarının öğrenme yaklaşımları ve ölçme ve değerlendirme tercihleri arasındaki ilişkinin incelenmesi amaçlanmıştır. Böylelikle araştırmanın alan yazına katkıda bulunacağı düşünülmektedir.

\section{Araştırma Sorusu}

$\mathrm{Bu}$ çalışmanın araştırma sorusu şöyledir: Öğretmen adaylarının öğrenme yaklaşımları ile ölçme ve değerlendirme tercihleri arasında nasıl bir ilişki vardır?

\section{Yöntem}

\section{Araştırma Deseni}

$\mathrm{Bu}$ çalışmada ilişkisel tarama modeli kullanılmıştır. Bu araştırma modeli, iki ya da daha çok değişken arasında ilişki olup olmadığını ve var ise derecesini belirlemeyi amaçlamaktadır (Erkuş, 2012; Fraenkel \& Wallen, 2006; Karasar, 1986).

\section{Çalışma Grubu}

Bu çalışmaya, Türkiye'deki bir eğitim fakültesinde 2016-2017 eğitim-öğretim yılında öğrenim gören 2., 3. ve 4. sınıf öğretmen adayları katılmıştır. Öğretmen adayları farklı bölümlerde öğrenim görmektedir. Adayların 193’ü (\%73) kadın, 71'i (\%27) ise erkektir. Öğretmen adaylarının demografik özellikleri Tablo 1'de özetlenmiştir.

Tablo 1

Öğretmen Adaylarının Demografik Özellikleri

\begin{tabular}{|c|c|c|}
\hline Bölümler & $\mathrm{N}$ & $\%$ \\
\hline Okul Öncesi Eğitimi & 80 & 30.3 \\
\hline Sınıf Eğitimi & 68 & 25.8 \\
\hline Fen Bilimleri Eğitimi & 59 & 22.3 \\
\hline Sosyal Bilgiler Eğitimi & 57 & 21.6 \\
\hline \multicolumn{3}{|l|}{ Cinsiyet } \\
\hline Kadın & 193 & 73 \\
\hline Erkek & 71 & 27 \\
\hline Genel & 264 & 100 \\
\hline
\end{tabular}

\section{Veri Toplama Aracı}

$\mathrm{Bu}$ çalışmada veri toplama aracı olarak Düzenlenmiş İki Faktörlü Çalışma Süreci Ölçeği (DÇSÖ-2F) ve Ölçme ve Değerlendirme Tercihleri Ölçeği (ÖDTÖ) kullanılmıştır.

Düzenlenmiş İki Faktörlü Çalışma Süreci Ölçeği (DÇSÖ-2F): Biggs, Kember ve Leung (2001) tarafından geliştirilen Düzenlenmiş İki Faktörlü Çalışma Süreci Ölçeği (DÇSÖ-2F), Önder ve Beşoluk (2010) tarafından Türk kültürüne adapte edilmiştir. DÇSÖ-2F, 5'li likert tipinde 20 maddeden oluşan bir ölçektir. Derin Öğrenme (DÖ) 
yaklaşımı (10 madde) ve Yüzeysel Öğrenme (YÖ) yaklaşımı (10 madde) olmak üzere iki alt boyuttan oluşmaktadır. Her bir boyut kendi içinde "Strateji" ve "Güdü" olmak üzere iki alt boyuttan oluşmaktadır (DS: Derin Strateji; DG: Derin Güdü; YG: Yüzeysel Güdü; YS: Yüzeysel Strateji). Ölçeğin geliştirilme çalışmasında yapılan doğrulayıcı faktör analizi sonucunda iki faktörlü modelin kabul edilir uyum değerlerine sahip olduğu ortaya çıkmıştır. Ayrıca orijinal ölçeğin ölçüm sonuçlarının güvenirliğe ilişkin Croanbach Alfa değerlerinin her bir boyut ve alt boyutlar için ( $\mathrm{DÖ}=73, \mathrm{DG}=.62, \mathrm{DS}=$ $.63, \mathrm{YO}=.64, \mathrm{YG}=.72$ ve $\mathrm{YS}=.57) \mathrm{kabul}$ edilir değerler olduğu belirtilmiştir. Önder ve Beşoluk'un (2010) Türkçe'ye uyarlama çalışmasında yapmış olduğu doğrulayıcı faktör analizi sonuçları, 20 maddeden oluşan iki faktörlü yapının uyum iyiliği değerlerinin iyi düzeyde olduğunu göstermiştir $(\chi 2 / \mathrm{sd})=2.94, \mathrm{RMSEA}=.061, \mathrm{NFI}=.90, \mathrm{CFI}=.93$, $\mathrm{IFI}=.93, \mathrm{RFI}=.88$, GFI=.92, AGFI=.89). Araştırmacılar güvenirlik çalışmaları için testtekrar test yöntemi ve iç tutarlılık yöntemlerinden faydalanmıştır. Test-tekrar test yöntemi ile Pearson Korelasyon katsayısı .82 olarak bulunmuştur. Croanbach Alfa katsayısın 1 ise $\mathrm{DG}=.64, \mathrm{DS}=.58, \mathrm{YG}=.61, \mathrm{YS}=.52, \mathrm{DO}=.78, \mathrm{YO}=.74$ olarak hesaplamışlardır. Genel olarak uyarlama sonucunda, geçerlik ve güvenirlik ölçüm sonuçlarının kabul edilir düzeyde olduğu belirtilmiştir.

Ölçme ve Değerlendirme Tercihleri Ölçeği (ÖDTÖ): Birenbaum (1997) tarafından geliştirilen Ölçme ve Değerlendirme Tercihleri Ölçeği (ÖDTÖ), Gülbahar ve Büyüköztürk (2008) tarafindan Türk kültürüne adapte edilmiştir. Üniversite öğrencilerinin ölçme ve değerlendirme tercihlerini ölçen ÖDTÖ, 5'li likert tipinde olup 72 maddeden oluşmaktadır. Ölçme ve değerlendirme yöntemlerine ilişkin boyutlar, öğrencilere ilişkin boyutlar ve sınav alma, notlandırma ve raporlaştırma olmak üzere birbirinden bağımsız olarak kullanılabilen üç alt boyuttan oluşmaktadır. Araştırmacılar uyarlama sürecinde herbir alt boyut için geçerlik ve güvenirlik çalışması yapmışlardır. $\mathrm{Bu}$ çalışmada, ölçme ve değerlendirme yöntemlerine ilişkin boyutlar kullanılmıştır. Bu boyutların alt ölçeklerini; değerlendirme türleri alt ölçeği ve madde biçimi-işlem türü alt ölçeği oluşturmuştur. Geleneksel ölçme ve değerlendirme faktörü (12 madde) ve alternatif ölçme ve değerlendirme faktöründen ( 5 madde) oluşan değerlendirme türleri alt ölçeği için doğrulaycı faktör analizi yapılmıştır. Çalışmada güvenirlik analizi için Croanbach Alfa değerleri; geleneksel ölçme ve değerlendirme faktörü için .86, alternatif ölçme ve değerlendirme faktörü için .67 olarak hesaplanmıştır. Uyarlama çalışmasında, basit/seçmeli faktörü ( 8 madde) ve karmaşık/ yapılandırmacı faktöründen (5 madde) oluşan madde biçimi-işlem türü alt ölçeği için de doğrulayıcı faktör analizi yapılmıştır. Güvenirlik analizinde Croanbach Alfa katsayısı; basit/seçmeli faktörü için .75, karmaşık/ yapılandırmacı faktörü için .58 olarak hesaplanmıştır.

\section{Veri Analizi}

Araştırmada öğretmen adaylarının öğrenme yaklaşımları ile ölçme ve değerlendirme tercihleri arasındaki ilişki kanonik korelasyon analizi ile incelenmiştir. Regresyon analizine benzer olarak kullanılan kanonik korelasyon analizi, çoklu regresyon analizidir. İleri düzeyde ilişki analizi olarak kabul edilen kanonik korelasyon analizinde birden fazla bağımlı ve bağımsız değişken arasındaki ilişki incelenmektedir (Morrison, 1976; Özçomak \& Demirci, 2010; Tabachnick, 1996). Bu çalışmada kanonik korelasyon analizi ile bağımsız değişken kümesinin bağımlı değişken kümesini ne derecede açıklayabildiğini ortaya çıkarmak amaçlanmaktadır. Tek değişkenli analiz 
yöntemlerine kıyasla kanonik korelasyon analizi, değişken setleri arasındaki ilişkiyi maksimum şekilde hesaplamaktadır. Dolayısıyla bu analiz yöntemi, araştırmanın geçerliğini olumsuz yönde etkileyen 1. Tip Hata'nın (Type I Error) artmasını önlemektedir (Rencher, 2002; Thompson, 2000). Çalışmada verinin kanonik korelasyon analizi için gerekli olan bazı varsayımları karşılayıp karşılamadığı test edilmiştir. Verilerin çok değişkenli normal dağılım gösterip göstermediği incelenmiştir. Veri setinde uç değerler ve eşvaryanslık incelemesi yapılmıştır. Kanonik korelasyon analizinde araştırmanın güvenirliğini arttırabilmek için örneklem sayısının veri setindeki toplam değişken sayısının en az 20 katı kadar olması önerilmektedir (Stevens, 2009). Bu araştırmada birinci değişken setinde (öğretmen yaklaşımları) 2 adet değişken, ikinci değişken setinde (ölçme ve değerlendirme tercihleri) ise 4 adet değişken bulunmaktadır. Veri setlerinde toplam 6 adet değişken olduğu için en az 120 katılımcıya ulaşılması gerekmektedir. Bu çalışmada katılımcı sayısı 264'tür. Buna göre araştırma sonucu elde edilen bulguların güvenirliği açısından örneklem sayısının yeterli olduğu söylenebilir. Ayrıca çoklu bağlantı olup olmadığını belirlemek için (multicollinearity), değişkenler arasındaki Pearson Korelasyonu'na bakılmıştır. Korelasyon değerlerinin 0.7'den yüksek çıkmaması çoklu bağlantı olmadığına işaret etmiştir. Ayrıca bağımsız değişkenlerin Tolerans ve VIF değerleri incelenmiştir. Tolerans değerlerinin 0.10'dan küçük olmadiğ 1 ve VIF değerlerinin de 10'dan büyük olmaması nedeniyle çoklu bağlantı olmadığına karar verilmiştir (O’Brien, 2007). Kanonik korelsayon analizine göre en az değişkene sahip veri setine göre iki adet kanonik korelasyon fonksiyonu oluşturulmuş ve bu fonksiyonlara ait kanonik korelasyon değerleri hesaplanmıştır.

\section{Bulgular}

$\mathrm{Bu}$ çalışmada kanonik korelasyon analizi ile öğretmen adaylarının öğrenme yaklaşımları ve ölçme ve değerlendirme tercihlerine yönelik veri setleri arasındaki ilişkiler ortaya çıkarılmıştır. Tablo 2'deki bulgulara göre analiz sonucunda iki kanonik fonksiyondan oluşan kanonik model istatistiksel olarak anlamlıdır. Birinci kanonik korelasyon çifti [Wilks's lamda $=.774, \mathrm{~F}(8,516)=8.809, p<.001$ ] ve birinci kanonik fonksiyonun çıkarılmasından sonra oluşan ikinci kanonik korelasyon çifti [Wilks's lamda $=.953, \mathrm{~F}(3,259)=4.237, p<.001]$ istatistiksel olarak anlamlıdır. Birinci kanonik fonksiyona ilişkin kanonik korelasyon değeri anlamlı olup .433'dür. Veri setleri arasında paylaşılan ortak varyans ise kanonik korelasyon değerlerinin karelerinin alınmasıyla elde edilmiştir (Sherry \& Henson, 2005). Buna göre, birinci kanonik fonksiyona ait veri setleri arasında açıklanan varyans değeri 187 olup veri setleri arasında paylaşılan ortak varyansın \%19 olduğu söylenebilir. İkinci kanonik fonksiyon için hesaplanan kanonik korelasyon değeri de anlamlı olup .216'dır. Veri setleri ikinci kanonik korelasyonda sadece \%5'lik bir varyans paylaşmaktadır. 
Tablo 2

Kanonik Korelasyon Analizi Sonuçları

\begin{tabular}{lcccccc}
\hline & $\begin{array}{c}\text { Öz } \\
\text { Değer }\end{array}$ & $\begin{array}{c}\text { Kanonik } \\
\text { Korelasyon }\end{array}$ & $\begin{array}{c}\text { Kanonik } \\
\text { korelasyonun } \\
\text { karesi }\end{array}$ & F & $p$ & \multicolumn{2}{c}{ Wilk's lambda } \\
Değeri
\end{tabular}

Araştırmada analiz sonucunda, öğretmen adaylarının öğrenme yaklaşımları veri setinin alt faktörlerinde yer alan derin öğrenme yaklaşımı (DÖY) ve yüzeysel öğrenme yaklaşımı (YÖY) değişkenleri ile öğretmen adaylarının ölçme ve değerlendirme tercihleri veri setinin alt faktörlerinde yer alan geleneksel değerlendirme (GD), alternatif değerlendirme (AD), basit/seçmeli madde tipi (BSM), karmaşı/oluşturmacı madde tipi (KOM) değişkenlerine ilişkin hesaplanan standardize edilmiş kanonik katsayılar ve kanonik korelasyon katsayıları Tablo 3'te verilmiştir. Veri setinde yer alan değişkenleri yorumlarken kanonik modele katkıda bulunabilmesi için kanonik yük değerleri .30'un üzerinde olanlar dikkate alınmıştır (Tabachnick \& Fidell, 2007). Ayrıca kanonik değişkenlerin yük değerlerinin yanında yönleri de yorumlanmıştır.

Tablo 3

Öğretmen Adaylarının Öğrenme Yaklaşımları ile Ölçme ve Değerlendirme Tercihleri Arasındaki İlişkiye Yönelik 1. ve 2. Kanonik Fonksiyon için Kanonik Çözümleme

\begin{tabular}{|c|c|c|c|c|}
\hline & \multicolumn{2}{|c|}{ Birinci kanonik fonksiyon } & \multicolumn{2}{|c|}{ İkinci kanonik fonksiyon } \\
\hline & $\begin{array}{c}\text { Standardize } \\
\text { edilmiş } \\
\text { kanonik } \\
\text { katsayılar }\end{array}$ & Korelasyon & $\begin{array}{c}\text { Standardize } \\
\text { edilmiş } \\
\text { kanonik } \\
\text { katsayılar }\end{array}$ & Korelasyon \\
\hline \multicolumn{5}{|l|}{ Öğrenme yaklaşımları } \\
\hline Derin öğrenme yaklaşımı (DÖY) & .786 & .901 & -.672 & -.433 \\
\hline Yüzeysel öğrenme yaklaşımı (YÖY) & -.448 & -.650 & -.933 & -.760 \\
\hline \multicolumn{5}{|l|}{ Ölçme ve değerlendirme tercihleri } \\
\hline Geleneksel değerlendirme (GD) & -.092 & -.275 & -.709 & -.706 \\
\hline Alternatif değerlendirme (AD) & .904 & .954 & -.324 & -.261 \\
\hline Basit/Seçmeli madde tipi (BSM) & -.218 & .114 & -.588 & -.632 \\
\hline $\begin{array}{l}\text { Karmaşı/k/oluşturmacı madde tipi } \\
(\mathrm{KOM})\end{array}$ & .220 & .624 & .290 & .148 \\
\hline Kanonik korelasyon & & .433 & & .216 \\
\hline $\mathrm{R}^{2}$ (Açıklanan varyans) & & .187 & & .046 \\
\hline
\end{tabular}


Tablo 3'te yer alan bulgulara göre; birinci kanonik fonksiyonda DÖY ve YÖY değişkenlerinin öğrenme yaklaşımları veri setine olan katkılarının anlamlı olduğu ancak DÖY değişkeninin kanonik yük değerinin (.901) YÖY değişkenine (-.65) göre daha yüksek değer alarak ön plana çıktığı görülmektedir. Ayrıca öğrenme yaklaşımları veri setinde, DÖY ve YÖY değişkenleri arasında negatif bir ilişki olduğu tespit edilmiştir. Buna göre veri setinde, DÖY değişkeni arttıkça YÖY değişkeninin azaldığı söylenebilir. Birinci kanonik fonksiyonda değerlendirme tercihleri veri setinde yer alan değişkenler incelendiğinde ise; $\mathrm{AD}$ (.954) ve KOM (.624) değişkenlerinin katkılarının anlamlı olduğu söylenebilir. Ölçme ve değerlendirme veri setine anlamlı katkıları olan AD ve KOM değişkenleri arasında pozitif yönde bir ilişki bulunmaktadır. Ayrıca DÖY ile AD ve KOM değişkenleri arasında pozitif yönde; YÖY ile AD ve KOM değişkenleri arasında ise negatif yönde bir ilişki bulunmaktadır. Birinci kanonik modele ilişkin sonuçlara göre, derin öğrenme yaklaşımını (DÖY) benimseyen öğretmen adaylarının alternatif değerlendirme yöntemini (AD), karmaşık/oluşturmacı madde tipini (KOM) daha çok tercih ettikleri söylenebilir. Ancak yüzeysel öğrenme yaklaşımını benimseyen öğretmen adaylarının alternatif değerlendirme yöntemini ve karmaşı/oluşturmacı madde tipini ise daha az tercih ettikleri söylenebilir. Öğrenme yaklaşımları ile ölçme ve değerlendirme tercihleri veri setleri arasındaki birinci kanonik fonksiyona ilişkin yapısal katsayılar Şekil 1'de de gösterilmiştir.

Şekil 1. Öğrenme Yaklaşımları ile Ölçme ve Değerlendirme Tercihleri Arasındaki 1. Kanonik Fonksiyona ait Yapısal Katsayılar

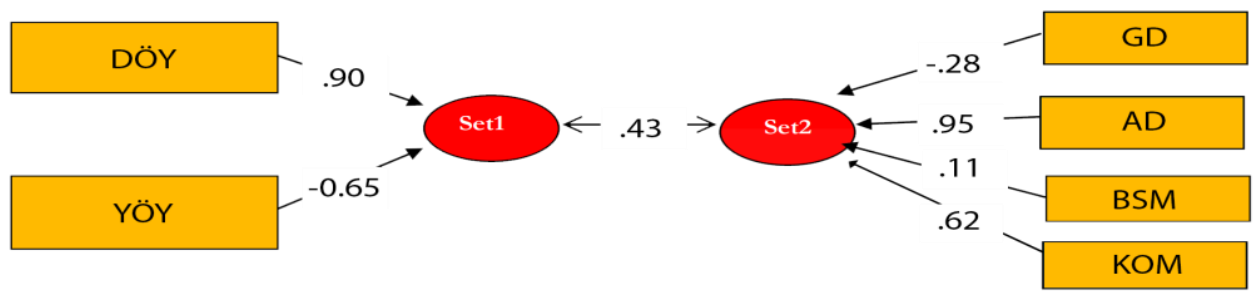

Tablo 3'te özetlenen ikinci kanonik fonksiyona ilişkin bulgular incelendiğinde; öğrenme yaklaşımları veri setindeki kanonik yük değerine göre DÖY (-.433) değişkeninin ve YÖY (-.760) değişkeninin katkılarının anlamlı olduğu ve değişkenler arasında aynı yönlü bir ilişsi olduğu tespit edilmiştir. Yine ikinci kanonik fonksiyona ilişkin bulgulara göre, değerlendirme tercihleri veri setinde GD (-.706) ve BSM (-.632) değişkenlerinin katkılarının yüksek olduğu görülmektedir. İkinci kanonik fonksiyonda öğrenme yaklaşımları veri setine ait DÖY ile YÖY değişkenleri ile değerlendirme tercihleri veri setine ait GD ve BSM değişkenlerinin yönleri incelendiğinde aynı yönlü bir ilişki bulunmaktadır. $\mathrm{Bu}$ sonuca göre, derin öğrenme ve yüzeysel öğrenme yaklaşımını benimseyen öğretmen adaylarının geleneksel değerlendirme yöntemi, basit/seçmeli madde tipini daha çok tercih ettikleri söylenebilir. Ancak çalışmada yüzeysel öğrenme yaklaşımını kullanan öğretmen adaylarının geleneksel değerlendirme yöntemini ve basit/seçmeli madde tipini tercih etme düzeyleri arasındaki ilişkilerin derin öğrenme yaklaşımını kullanan öğretmen adaylarına göre daha yüksek olduğu söylenebilir. Öğrenme yaklaşımları ile ölçme ve değerlendirme tercihleri veri setleri 
arasındaki ikinci kanonik fonksiyona ilişkin yapısal katsayılar Şekil 2'de ayrıca gösterilmiştir.

Şekil 2. Öğrenme Yaklaşımları ile Ölçme ve Değerlendirme Tercihleri Arasındaki 2. Kanonik Fonksiyona ait Yapısal Katsayılar

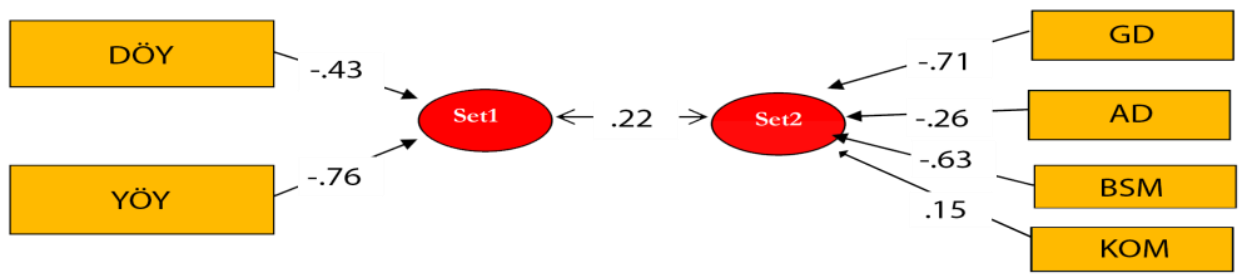

Çalışmada, öğrenme yaklaşımları ve değerlendirme tercihleri veri setlerinin paylaştıkları ortak paydaşların ne kadar olduğu ise birinci ve ikinci kanonik fonksiyona ait hesaplanmış $\mathrm{R}^{2}$ değerlerinin toplanmasıyla elde edilmiştir (Şekil 3). Buna göre, öğrenme yaklaşımları veri seti ile değerlendirme tercihleri veri setleri arasında paylaşılan ortak varyans \%24'tür.

Şekil 3. Öğrenme Yaklaşımları ile Değerlendirme Tercihleri Arasında Paylaşılan Ortak Varyans

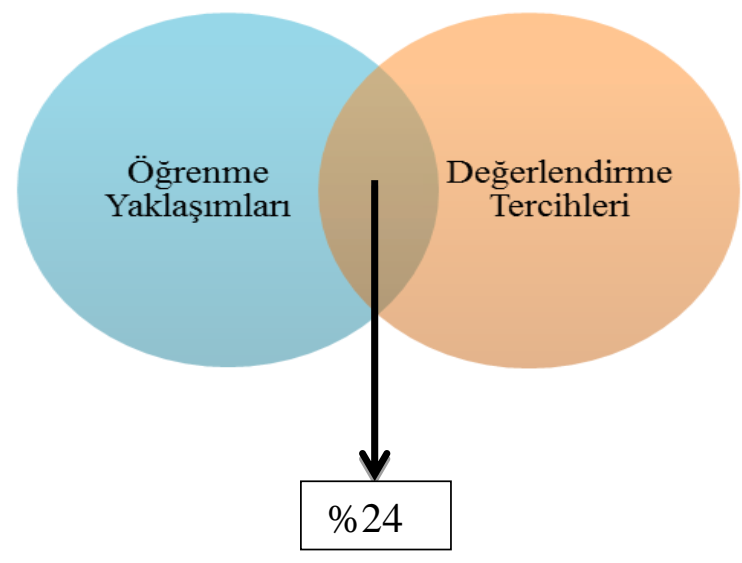

\section{Sonuç ve Tartışma}

$\mathrm{Bu}$ araştırma, öğretmen adaylarının öğrenme yaklaşımları ile ölçme ve değerlendirme tercihleri arasındaki ilişkiyi belirlemeyi amaçlamaktadır. Kanonik korelasyon analizi sonucuna göre, öğretmen adaylarının öğrenme yaklaşımları ve değerlendirme tercihleri arasında anlamlı bir ilişki olduğu ortaya çıkmıştır. Adayların benimsedikleri öğrenme yaklaşımlarına göre ölçme ve değerlendirme tercihlerinin farklılık gösterdiği görülmektedir. Öğrenme yaklaşımları ile değerlendirme tercihleri veri setleri arasında paylaşılan ortak varyans \%24 olarak hesaplanmıştır. Birinci kanonik fonksiyondan elde edilen bulgular, öğrenme yaklaşımı veri setinde derin öğrenme yaklaşımı (DÖY) değişkeninin yüzeysel öğrenme yaklaşımı (YÖY) değişkenine göre daha güçlü bir etkiye sahip olduğunu ve aralarında negatif bir ilişki 
olduğunu göstermiştir. Buna göre, öğretmen adaylarının derin öğrenme yaklaşımı kullanma düzeyleri arttıkça yüzeysel öğrenme yaklaşımını daha az tercih ettikleri söylenebilir. Değerlendirme veri setinde ise, alternatif değerlendirme (AD) ve karmaşık/oluşturmacı madde tipi (KOM) değişkenlerinin geleneksel değerlendirme (GD) ve basit/seçmeli madde tipi (BSM) değişkenlerine göre daha güçlü bir etkiye sahip olduğu ortaya çıkmıştır. Ayrıca birinci kanonik fonksiyonda, derin öğrenme yaklaşımı (DY) değişkeninin alternatif değerlendirme (AD) ve karmaşık/oluşturmacı madde tipi (KOM) değişkenleri ile aralarında pozitif yönde güçlü bir ilişki olduğu ortaya çıkmıştır. $\mathrm{Bu}$ araştırma sonucuna göre, derin öğrenme yaklaşımını benimseyen öğretmen adaylarının daha çok alternatif değerlendirme yöntemlerini tercih ettikleri ve karmaşık/oluşturmacı madde tipindeki soruları kullanma eğiliminde oldukları söylenebilir. İkinci kanonik fonksiyondan elde edilen bulgular ise, hem yüzeysel öğrenme hem de derin öğrenme yaklaşımını kullanan öğretmen adaylarının daha çok geleneksel değerlendirme yöntemlerini ve basit/seçmeli madde tipindeki soruları tercih etme eğiliminde olduklarını göstermiştir. Ancak, yüzeysel öğrenme yaklaşımını benimseyen öğretmen adaylarının derin öğrenme yaklaşımına kıyasla geleneksel değerlendirme yöntemlerini ve bununla ilişkili olan basit/seçmeli sınav türlerini tercih etme düzeylerinin daha yüksek olduğu tespit edilmiştir.

Genel olarak araştırma, öğretmen adaylarının benimsemiş oldukları derin öğrenme yaklaşımı ya da yüzeysel öğrenme yaklaşımı ile ölçme ve değerlendirme tercihleri arasında anlamlı ilişki olduğunu ortaya koymuştur. Bu sonuçların birçok araştırmayla desteklendiği görülmektedir (Birenbaum \& Feldman, 1998; Birenbaum \& Rosenau 2006; Doğan, Atmaca, \& Aslan-Yolcu, 2012; Gijbels \& Dochy, 2006; Sambell, McDowell, \& Brown, 1997; Segers, Martensa, \& Bossche, 2008). Günümüz öğrenme ortamı, yapılandırmacı öğrenme kuramının etkisiyle derin ve anlamlı şekilde öğrenen öğrencileri hedeflemektedir (Fyrenius, Bergdahl, \& Silen, 2005). Bu nedenle, öğrencileri yüzeysel öğrenmeden ziyade derin öğrenmeye teşvik eden öğretim uygulamaları ve ölçme değerlendirme yöntemleri oldukça önem kazanmıştır (Segers Dochy, \& Cascallar, 2003; Trigwell \& Prosser, 1991). Bu araştırmada, öğretmen adaylarının çoğunluğunun derin öğrenme yaklaşımını benimsemesi ve buna uygun olan alternatif değerlendirme yöntemini ve karmaşı/oluşturmacı sınav türlerini tercih etmeleri yaşam boyu öğrenme için gerekli eğitimi aldıklarının bir göstergesi olabilir. Çünkü öğretmen yetiştirme programlarında verilen eğitim, öğretmen adaylarının öğrenme yaklaşımlarını ve başarılarını etkileyen önemli bir faktördür (Biggs, 2003). Her ne kadar araştırmada öğretmen adaylarının çoğunluğu derin öğrenme yaklaşımını benimseyip buna uygun olan alternatif değerlendirme yöntemlerini tercih etse de adayların bir kısmının yüzeysel öğrenmeyi benimsediği ve bu yaklaşıma uygun geleneksel değerlendirme yöntemlerini tercih ettikleri görülmektedir. Yapılandırmacı öğrenme kuramına göre oluşturulan öğrenme-öğretme ve ölçme ve değerlendirme ortamında derin öğrenme her zaman doğrudan gerçekleşmeyebilir. Bu süreç oldukça karmaşıktır. $\mathrm{Bu}$ nedenle, öğretmen yetiştirme programlarında öğrenme-öğretme ortamının ve ölçme ve değerlendirme uygulamalarının adayların derin öğrenme gelişimine katkıda bulunacak şekilde düzenlemesi oldukça önemlidir. Bu alana yönelik araştırmaların arttırılarak öğretmen adaylarının öğrenme, öğretme ve ölçme ve değerlendirme yöntemlerine yönelik düşüncelerinin ve tercihlerinin incelenmesi gerekmektedir. 


\section{Summary}

Introduction: In the twenty first century, the aim of the higher education is to help university students develop lifelong skills such as critical thinking, making analysis, synthesis and inferences. In order to reach higher order skills, adopting deep learning approach is very important for students (Asikainen, 2014; Segers et al., 2003). Several factors can influence students' learning approaches. Students' deep or surface learning approaches depend on their tasks during the teaching-learning process (Biggs, 2001; Ramsden, 1984; Segers et al., 2008 Ünal \& Ergin, 2006) and assessment methods used in the courses (Gibbs, 1999; Ramsden, 1992; Scouller \& Prosser, 1994; Trigwell \& Prosser, 1991). Students' perceptions to these factors and students' individual characteristics can also influence their learning approaches (Gijbels et al, 2014).

With the effect of constructivist learning theory, instruction and assessment have changed considerably. Assessment as an important tool for learning promotes deep learning (Dochy \& McDowell, 1997; Gulikers et al, 2006). Therefore, understanding learners' thoughts and preferences about teaching, learning, and assessment methods are very important to improve the quality of education (Sander et al., 2000). Only a few number of studies have reported that there exists a relationship between students' approaches to learning and their assessment preferences (Birenbaum 1997; Birenbaum \& Feldman, 1998; Birenbaum \& Rosenau, 2006; Doğan, Atmaca, \& Aslan, 2012; Gijbels \& Dochy, 2006; Gijbels et al., 2008; Schouller, 1998; Segers et al, 2006; Segers et al., 2008). More research in this area is needed to be done in order to develop a better understanding of students' approaches to learning and their assessment demands.

The current study aims to find out the correlation between learning approaches and assessment preferences of pre-service teachers. Since few studies have been done in this specific topic, the finding of the study is expected to make a significant contribution to the literature.

Method: Relational model was used in this study in order to analyze the relationship between variables (Erkuş, 2012; Fraenkel \& Wallen, 2006; Karasar, 1986). The participants of the study consisted of 264 pre-service teachers who enrolled in one of the teacher education programs in Turkey during the 2016-2017 academic year. Data were collected by the implementation of two different scales. In order to assess pre-service teachers' approaches to learning, a scale entitled "Revised Two-factor Study Process Questionnaire" was used. This scale developed originally by Biggs, Kember, \& Leung (2001) was adapted to Turkish culture by Önder \& Beşoluk (2010). To assess preservice teachers' assessment preferences, a scale entitled "Assessment Preferences Inventory" was utilized. This scale developed originally by Birenbaum (1997) was adapted to Turkish culture by Gülbahar \& Büyüköztürk (2008).

Findings: Canonical correlation analysis was used in this study to determine the relationship between learning approaches data set composed of deep approach to learning and surface approach to learning variables and assessment preferences data set composed of traditional, alternative, complex-constructivist, and simple-multiple choice variables. Some of the assumptions for canonical correlation analysis were examined 
before the analysis. The results indicated that the assumptions were all met with the data.

The results of the canonical analysis showed that first and second variable pairs were observed to be significant [Wilks's lamda $=.774$, F $(8,516)=8.809, p<.001$; Wilks's lamda $=.953, \mathrm{~F}(3,259)=4.237, p<.001]$. In the first canonical function, canonical correlation was calculated to be .433 . Shared variance between learning approach data set and assessment preference dataset was 19\%. In the second canonical function, canonical correlation was calculated to be .216. Shared variance between two dataset was $5 \%$. In the first canonical function, the contributions of deep learning approach variable (.901) and surface learning approach variable (-.650) to the learning approach data set were significant. In the assessment preference data set, the contributions of alternative assessment variable (.954), complex-constructivist assessment variable (.624) were significant. This result showed that pre-service teachers using deep learning approach are more likely to prefer alternative assessment method and complexconstructivist items. In the second canonical function, the contributions of deep learning approach variable (-.433) and surface learning approach variable (-.760) to the learning approach data set were significant. However, traditional assessment variable (-.706) and simple-multiple choice assessment variable (-.632) were significant contributions in assessment preference data set. It can be argued that pre-service teachers using surface learning approach mostly are less likely to prefer alternative assessment method and complex-constructivist items. Furthermore, variance shared between learning approach and assessment preference datasets was calculated as $24 \%$.

Conclusion: Consequently, the results of the study showed that significant relationships existed between approaches to learning and assessment preferences of pre-service teachers. It can be interpreted that pre-service teachers who use deep learning approach are more likely to prefer alternative assessment method and complex-constructivist items. These results were in line with other research findings (Birenbaum \& Feldman, 1998; Birenbaum \& Rosenau, 2006; Doğan, Atmaca, \& Aslan-Yolcu, 2012; Gijbels \& Dochy, 2006; Sambell et al., 1997; Segers et al., 2008). 


\section{Kaynakça}

Al-Kadri, H., Almoamary, M., Roberts, C., \& Van der Vleuten, C. (2012). Exploring assessment factors contributing to students study strategies: Literature review. Med Teach, 34(1), 42-50.

Asikainen, H. (2014). Successful learning and studying in the biosciences. Exploring how students' conceptions of learning, approaches to learning, motivation and their experiences of the teaching-learning environment are related to study success (Doctoral dissertation). University of Helsinki, Finland.

Baeten, M., Dochy, F., \& Struyven, K. (2008). Students' approaches to learning and assessment preferences in a portfolio-based learning environment. Instructional Science, 36, 359-374.

Biggs J.B. (1987). Student approaches to learning and studying. Australia Council for Edu. Research, Hawthorn, VIC.

Biggs, J. (1996). Enhancing teaching through constructive alignment. Higher Education, 32(3), 347-364.

Biggs, J. (2001). Enhancing learning: A matter of style or approach. In R. J. Sternberg \& L. Zhang (Eds.), Perspectives on thinking, learning, and cognitive styles (pp. 73102). Marwah, NJ: Lawrence Erlbaum.

Biggs, J. B. (2003). Teaching for quality learning at university. Buckingham: Open University Press/Society for Research into Higher Education. (Second edition)

Biggs, J., Kember, D., \& Leung, D.Y.P. (2001). The revised two-factor study process questionnaire: R-SPQ-2F. British Journal of Educational Psychology, 71, 133-149.

Biggs J.B., \& Moore P.J. (1993). The process of learning (3rd ed.). Sydney: Prentice Hall, Australia.

Biggs, J.B., \& Tang, C. (2007). Teaching for quality learning at university. Maidenhead: McGraw Hill Education \& Open University Press. (3rd Edition).

Birenbaum, M. (1997). Assessment preferences and their relationship to learning strategies and orientations. Higher Education, 33, 71-84.

Birenbaum, M. (2007). Assessment and instruction preferences and their relationship with test anxiety and learning strategies. Higher Education, 53(6), 749-768.

Birenbaum, M., \& Feldman, R.A. (1998). Relationships between learning patterns and attitudes towards two assessment formats. Educational Research, 40(1), 90-7.

Birenbaum, M., \& Rosenau, S. (2006). Assessment preferences, learning orientations, and learning strategies of pre-service and in-service teachers. Journal of Education for Teaching, 32(2), 213-225.

Byrne, M., Flood, B., \& Willis, P. (2002). The relationship between learning approaches and learning outcomes: a study of Irish accounting students. Accounting Education, 11(1), 27-42.

De Corte, E. (1996). Active learning in powerful learning environments. Impuls, 26(4), $145-156$.

Diseth, A., \& Martinsen, O. (2003). Approaches to learning, cognitive style and motives as predictors of academic achievement. Educational Psychology, 23, 196-207. 
Dochy, F. \& Mc Dowell, L. (1997) Assessment as a tool for learning, Studies in Educational Evaluation, 23(4), 279-298.

Doğan, C. D., Atmaca, S., \& Aslan, F. (2012). The correlation between learning approaches and assessment preferences of 8th grade students. Illkögretim Online, 11(1), 264-272.

Erkuş, A. (2012). Psikolojide ölçme ve ölçek geliştirme. Ankara: Pegem Akademi Yayınları.

Fraenkel, J. R., \& Wallen, N. E. (2006). How to design and evaluate research in education (6. bask1). New York: McGraw Hill.

Fyrenius, A., Bergdahl, B., \& Sile'n, C. (2005). Lectures in problem-based learning why, when and how? An example of interactive lecturing that stimulates meaningful learning. Medical Teacher, 27(1), 61-65.

Gibbs, G. (1999). Using assessment strategically to change the way students learn, In: S. Brown \& A. Glasner (Eds) Assessment matters in higher education: choosing and using diverse approaches. Buckingham, Open University Press.

Gijbels, D., \& Dochy, F. (2006). Students' assessment preferences and approaches to learning: Can formative assessment make a difference? Educational Studies, 32(4), 401-11.

Gijbels, D., Donche, V., Richardson, J. T. E., \& Vermunt, J. D. (2014). Learning patterns in higher education. Dimensions and research perspectives. London: Routledge.

Gijbels, D., Segers, M., \& Struyf, E. (2008). Constructivist learning environments and the impossibility to change students' perceptions of assessment demands and approaches to learning. Instructional Science, 36, 431-443.

Gijbels, D., Van de Watering, G., Dochy, F. \& van den Bossche, P. (2005). The relationship between students' approaches to learning and learning outcomes. European Journal of Psychology of Education, 20(4), 327-341.

Gulikers, J., Bastiaens, T. J., Kirschner, P. A., \& Kester, L. (2006). Relations between student perceptions of assessment authenticity, study approaches and learning outcome. Studies in Educational Evaluation, 32(4), 381-400.

Goh P.S.C., Wong K.T., \& Osman R. (2012). Student-teachers' approaches to learning, academic performance and teaching efficacy. Malaysian Journal of Learning and Instruction, 9, 31-46.

Gülbahar, Y., \& Büyüköztürk, Ş. (2008). Değerlendirme tercihleri ölçeğinin Türkçe’ye uyarlanması. Hacettepe Üniversitesi Eğitim Fakültesi Dergisi, 35, 148-161.

Heikkilä, A., \& Lonka, K. (2006). Studying in higher education: students'approaches to learning, self-regulation, and cognitive strategies. Studies in Higher Education, 31(1), 99-117.

Karasar, N. (1986). Bilimsel araştırma yöntemi. Ankara: Bilim Yayınları.

Marton, F., \& Säljö, R. (1976). On qualitative differences in learning. II. Outcome as a function of the learner's conception of the task. British Journal of Educational Psychology, 46, 115-127. 
Morrison, D. F. (1976). Multivariate statistical methods. Mc Graw-Will Book Company, New York.

O'Brien, R.M. (2007). A caution regarding rules of thumb for variance inflation factors. Quality and Quantity Springer, 41, 673-690.

Önder, İ., \& Beşoluk, Ş. (2010). Düzenlenmiş iki faktörlü çalışma süreci ölçeğinin (RSPQ-2F) Türkçe'ye uyarlanması. Eğitim ve Bilim, 35(157), 55-67.

Özçomak, M.S., \& Demirci, A. (2010). Afrika birliği ülkelerinin sosyal ve ekonomik göstergeleri arasındaki ilişkinin kanonik korelasyon analizi ile incelenmesi. Atatürk Üniversitesi Sosyal Bilimler Enstitüsü Dergisi, 14(1), 261-274.

Ramsden, P. (1984). The context of learning. In F. Marton, D. Hounsell \& N. Entwistle (Eds.), The experience of learning. Edinburgh, Scotland: Scottish Academic Press.

Ramsden, P. (1992). Learning to teach in higher education. London: Routledge.

Ramsden, P., Beswick, D., \& Bowden, J.(1987) Learning processes and learning skills, In J.T.E. Richardson, M.W. Eysenck \& D.W. Warren-Piper (Eds.), Student Learning: research in education and cognitive psychology (pp. 168-176). Milton Keynes: Open University Press and Society for Research into Higher Education.

Rencher, C. A. (2002). Methods of multivariate analysis. New York: A John Wiley \& Sons, INC. Publication.

Sambell, K., McDowell, L., \& Brown, S. (1997). But is it fair?: An exploratory study of student perceptions of the consequential validity of assessment. Studies in Educational Evaluation, 23, 349-371.

Sander, P., Stevenson, K., King, M., \& Coates, D. (2000). University students' expectations of teaching. Studies in Higher Education, 25(3), 309-323.

Scouller, K. (1998). The influence of assessment method on students' learning approaches: Multiple choice question examination versus assignment essay. Higher Education, 35, 453-472.

Scouller, K., \& Prosser, M. (1994). Students' experiences in studying for multiple choice question examinations. Studies in Higher Education, 19, 267-279.

Segers, M., Dochy, F., \& Cascallar, E. (2003). Optimizing new modes of assessment: In search for qualities and standards. Boston, MA, Kluwer Academic Publishers.

Segers M., Martensa R., \& Bossche P. (2008). Understanding how a case-based assessment instrument influences student teachers' learning approaches. Teaching and Teacher Education, 24, 1751-1764.

Segers, M., Nijhuis, J., \& Gijselaers, W. (2006). Resigning a learning and assessment environment: The influence on students'perceptions of assessment demands and their learning strategies. Studies in Educational Evaluation, 32, 223- 242.

Sherry, A., \& Henson, R. K. (2005). Conducting and interpretin gcanonical correlation analysis in personality research: A user-friendly primer. Journal of Personality Assessment, 84(1), 37-48.

Stevens, J. P. (2009). Applied multivariate statistics for the social sciences. New York: Routledge.

Tabachnick, B. (1996). Using multivariate statistics. Harper Collins College Publishers, New York. 
Tabachnick, B.G., \& Fidell, L.S. (2007). Using multivariate statistics (5. bask1). Boston: Allyn and Bacon.

Thompson, B. (2000). Canonical correlation analysis. In Grimm L. G., \& Yarnold, P. R. (Eds.), Reading and understanding more multivariate statistics. Washington, DC: American Psychological Association.

Trigwell, K., \& Prosser, M. (1991) Relating approaches to study and quality of learning outcomes at the course level. British Journal of Educational Psychology, 61, 265275.

Ünal, G., \& Ergin, Ö. (2006). Buluş yoluyla fen öğretiminin öğrencilerin akademik başarılarına, öğrenme yaklaşımlarına ve tutumlarına etkisi. Türk Fen Eğitimi Dergisi, 3(1), 36-52.

Watkins, D. (2001). Correlates of approaches to learning: a cross-cultural meta-analysis. In R. J. Sternberg \& L. F. Zhang (Eds.), Perspective on thinking, learning and cognitive styles (pp. 165-195). Mahwah NJ: Lawrence Erlbaum Associates. 